\title{
Characteristics and outcomes of antiretroviral-treated HIV-HBV co-infected patients in Canada
}

Urvi Rana ${ }^{1,2}$, Matt Driedger ${ }^{3}$, Paul Sereda ${ }^{4}$, Shenyi Pan ${ }^{4}$, Erin Ding ${ }^{4}$, Alex Wong $^{5}$, Sharon Walmsley ${ }^{6}$, Marina Klein ${ }^{7}$, Deborah Kelly ${ }^{8}$, Mona Loutfy ${ }^{9}$, Rejean Thomas ${ }^{10}$, Stephen Sanche ${ }^{11}$, Abigail Kroch ${ }^{12}$, Nima Machouf ${ }^{13}$, Marie-Helene Roy-Gagnon ${ }^{1}$, Robert Hogg ${ }^{4}$, Curtis L. Cooper ${ }^{1,3^{*}}$ (D) and The Canadian Observational Cohort (CANOC) Collaboration

\begin{abstract}
Background: Hepatitis B (HBV) and Human Immunodeficiency Virus (HIV) share common risk factors for exposure. Co-infected patients have an increased liver-related mortality risk and may have accelerated HIV progression. The epidemiology and demographic characteristics of HIV-HBV co-infection in Canada remain poorly defined. We compared the demographic and clinical characteristics and factors associated with advanced hepatic fibrosis between HIV and HIV-HBV co-infected patients.

Methods: A retrospective cohort analysis was conducted using data from the Canadian Observational Cohort (CANOC) Collaboration, including eight sites from British Columbia, Quebec, and Ontario. Eligible participants were HIV-infected patients who initiated combination ARV between January 1, 2000 and December 14, 2014. Demographic and clinical characteristics were compared between HIV-HBV co-infected and HIV-infected groups using chi-square or Fisher exact tests for categorical variables, and Wilcoxon's Rank Sum test for continuous variables. Liver fibrosis was estimated by the AST to Platelet Ratio Index (APRI).

Results: HBV status and APRI values were available for 2419 cohort participants. 199 (8\%) were HBV co-infected. Compared to HIV-infected participants, HIV-HBV co-infected participants were more likely to use injection drugs ( $28 \%$ vs. $21 \%, p=0.03$ ) and be HCV-positive (31\%, vs. 23\%, $p=0.02)$. HIV-HBV co-infected participants had lower baseline CD4 T cell counts (188 cells/mm $/ \mathrm{mm}_{3}$ IQR: 120-360) compared to 235 cells $/ \mathrm{mm}_{3}$ in HIV-infected participants (IQR: $85-294)(p=0.0002)$ and higher baseline median APRI scores (0.50 vs. 0.37, $p<0.0001)$. This difference in APRI was no longer clinically significant at follow-up (0.32 vs. 0.30, $p=0.03$ ). HIV-HBV co-infected participants had a higher mortality rate compared to HIV-infected participants (11\% vs. 7\%, $p=0.02$ ).

Conclusion: The prevalence, demographic and clinical characteristics of the HIV-HBV co-infected population in Canada is described. HIV-HBV co-infected patients have higher mortality, more advanced CD4 T cell depletion, and liver fibrosis that improves in conjunction with ARV therapy. The high prevalence of unknown HBV status demonstrates a need for increased screening among HIV-infected patients in Canada.
\end{abstract}

Keywords: Co-infection, Hepatitis B, HIV, Prevalence

\footnotetext{
* Correspondence: ccooper@toh.ca

'School of Epidemiology and Public Health, University of Ottawa, Ottawa, ON

K1G 5Z3, Canada

${ }^{3}$ Department of Medicine, University of Ottawa, Ottawa, ON K1H 8M5,

Canada

Full list of author information is available at the end of the article
}

(c) The Author(s). 2019 Open Access This article is distributed under the terms of the Creative Commons Attribution 4.0 International License (http://creativecommons.org/licenses/by/4.0/), which permits unrestricted use, distribution, and reproduction in any medium, provided you give appropriate credit to the original author(s) and the source, provide a link to the Creative Commons license, and indicate if changes were made. The Creative Commons Public Domain Dedication waiver (http://creativecommons.org/publicdomain/zero/1.0/) applies to the data made available in this article, unless otherwise stated. 


\section{Background}

Approximately 40 million individuals are HIV-infected and an estimated 350 million people are infected with HBV (WHO, 2014). While the prevalence of HBV in Canada is decreasing due to immunization programs, it remains a public health issue partly as a consequence of the high prevalence among Canadian immigrants originating from HBV-endemic areas [1]. Other key at-risk groups in Canada include men who have sex with men (MSM), people who inject drugs (PWID), and Indigenous populations [1-4].

Due to shared routes of transmission including sexual contact, body fluid exposure, needle sharing, and vertical transmission, HIV-HBV co-infection is common $[5,6]$. Liver disease resulting from $\mathrm{HBV}$ infection is a leading cause of non-AIDS related morbidity and mortality among HIV-infected individuals on antiretroviral therapy (ARV) [7-10]. Co-infection with HIV is associated with an increased risk of HBV chronicity, cirrhosis, hepatocellular carcinoma and liver-related mortality among HBV-infected individuals $[1,11,12]$. There is conflicting evidence on whether HBV increases the rate of HIV progression $[10,13]$.

Over 75,000 Canadians live with HIV/AIDS and 6-8\% are HBV co-infected [14]. Data specific to HIV-HBV coinfection in Canada is sparse. Pittman et al. (2015) demonstrated a 5.5\% HBV prevalence in Northern Albertan HIV-positive patients [1]. Co-infected males tended to be White, and females were primarily Black and from HIV-endemic countries or Indigenous. A 2013 Ontariobased HIV cohort study suggested that HIV-HBV coinfected patients were more likely to be male and MSM [4]. While these studies provide important regional information on HIV-HBV co-infection, they cannot be generalized across Canada.

There is currently no Canadian-wide demographic or clinical data focusing on this population. To address this knowledge gap, we utilized a national cohort (Canadian Observational Cohort; CANOC) [15] of HIV-infected patients to explore the prevalence, demographic characteristics, risk factors for exposure, and clinical characteristics of HIV-HBV co-infection in Canada. We specifically evaluated predictors of liver fibrosis before and after initiating ARV therapy as well as mortality.

\section{Methods}

CANOC is an interprovincial collaboration of eight cohorts from British Columbia (BC), Quebec, and Ontario. Each site conducts data collection with local research ethics approval. Our participation in this study was submitted to and approved by the Ottawa Health Science Network Research Ethics Board (2010673-01H). Eligible participants were previously ARV treatment naïve HIVinfected patients who initiated combination ARV between January 1, 2000 and December 14, 2014 [15].
For this analysis we included only those participants from the CANOC cohort with complete HBV infection status and complete liver enzyme data, required for AST to Platelet Ratio Index (APRI) calculation. Baseline was defined as any time within 1 year prior to initiating first ARV therapy. Baseline values for CD4 T cell count and HIV viral load was obtained within 6 months prior to first ARV dosing date. End of follow-up period was defined as any time within 1 year before the patient's last follow date or December 31, 2014.

Participants were classified as 'HBV co-infected' if HBV surface antigen positive, HBV DNA positive, and/ or by physician report. The primary outcome, liver fibrosis stage, was calculated by the APRI, a validated noninvasive marker of fibrosis [16-18]. APRI was calculated using [AST/ (upper limit of normal AST)/platelets] $\times$ 100] [19]. The AST upper limit of normal was set at 40 IU/L. APRI ratios $\leq 0.50,0.51-1.49$, and $\geq 1.50$ were used to define minimal, intermediate, and clinically relevant fibrosis, respectively [17].

Demographic variables of interest included age, sex, ethnicity, province of residence, alive/deceased, as well as MSM and PWID status. HCV infection status was ascertained by serology, PCR, and/or physician report. AIDS-defining illnesses (ADI) were based on established criteria [20]. HIV viral suppression was defined as two consecutive viral load $<50$ copies/ml measured at least 30 days apart since the first naïve ARV date. HIV viral rebound included those who achieved viral suppression but went on to have 2 consecutive $\mathrm{VL}>200$ copies $/ \mathrm{ml}$ measured at least 30 days apart [1, 10-12, 21].

Demographic and clinical characteristics were compared between HIV-HBV co-infected and HIV-infected groups using chi-square or Fisher exact tests for categorical variables and Wilcoxon's Rank Sum test for continuous variables. Logistic regression models were developed to assess the association between HBV infection status and hepatic fibrosis, and to determine predictors of hepatic fibrosis at baseline and at end of follow-up. Variables that were statistically significant $(p<0.05)$ were then adjusted for in multivariable models.

\section{Results}

The final analysis set consisted of 2419 participants of which $8 \%(n=199)$ were HIV-HBV co-infected. Initially, a total of $10,477 \mathrm{HIV}$ positive participants were identified in the CANOC cohort. Participants from one cohort site $(n=1188)$ were excluded from analysis because of possible $\mathrm{HBV}$ misclassification concerns. Additionally, 2476 were excluded due to unknown HBV status and 4394 did not have AST data at both baseline and end of study. A comparison of the baseline characteristics study between those included in our study cohort and these excluded participants did not reveal any clinically 
relevant differences that we believe would impact our findings (see Additional file 1: Table S1).

Age, sex, ethnicity, MSM, and province of residence were similar between HIV-infected and HIV-HBV coinfected groups (Table 1). HIV-HBV co-infected participants were more likely to acquire HIV by injection drug use $(28 \%$ vs. $21 \%, p=0.03)$ and to be $\mathrm{HCV}$ co-infected (31\% vs $23 \% ; p=0.02$ ).

The median baseline CD4 T cell count was 188 cells/ $\mathrm{ml}$ in HIV-HBV co-infected participants (IQR: 120-360) and 235 cells/ml in HBV-negative participants (IQR: 85294) $(p=0.0002)$ (Table 2). The proportion with an AIDS-defining illness (ADI) on or before the first ARV treatment date was also higher in HIV-HBV co-infected patients $(28 \%$ vs. $20 \% p=0.01)$. The median duration of ARV therapy exposure was longer in the HIV-HBV coinfected group (5.97 years; IQR: 3.11-9.94 years) compared to HIV-infected individuals (5.01 years; IQR: $2.50-8.75$ years $)(p=0.003)$. The baseline and end-offollow up HIV viral load levels were similar between groups.

HIV-HBV co-infected patients had higher median APRI scores at baseline $(0.50$ vs. $0.37, p<0.0001)$ (Table 3). Overall, 6.5\% $(n=159)$ participants had clinically relevant fibrosis (APRI $\geq 1.5)$ at baseline. This proportion was higher (20\%) in those with HIV-HBV co-infection. While the rate of HIV RNA viral load suppression did not differ by APRI score, those with clinically relevant fibrosis were less likely to rebound following viral suppression ( $69 \%$ vs. $79 \%, p=0.05)$.

Individuals were more likely to have clinically relevant fibrosis at baseline if they were HBV (OR 3.08, 95\% CI: 1.99-4.78) or HCV co-infected (OR 4.55, 95\% CI: $3.26-$ 6.35) after adjusting for demographic characteristics (Table 4). Clinically relevant fibrosis was also associated with older age at first ARV date (OR 1.02, 95\% CI: 1.00 1.04) and baseline HIV RNA level $>5 \log 10$ copies (OR 2.15, CI: 1.16-3.97).

APRI scores declined once on ARV therapy, especially among HIV-HBV co-infected patients. Median APRI scores were only slightly greater among co-infected patients at end of follow-up (0.32 vs. 0.30, $p=0.03$ ) (Table $5)$. By multivariable analysis, HIV-HBV co-infection did not predict clinically relevant fibrosis at the end of follow-up. Clinically relevant fibrosis at end of follow-up was predicted by HCV co-infection, lower baseline CD4 $T$ cell counts and increased HIV RNA level at the end of study. We tested for HBV effect modification by including interaction terms in logistic regression models, and none were identified (data not shown).

Table 1 Demographic characteristics participants by HBV infection status $(N=2419)$

\begin{tabular}{|c|c|c|c|}
\hline Demographic Characteristics & $\begin{array}{l}\mathrm{HIV} \\
N=2220\end{array}$ & $\begin{array}{l}\text { HIV-HBV Co-Infection } \\
N=199\end{array}$ & $p$ value \\
\hline Median Age & $40(32.0-46.0)$ & $39(33.0-45.0)$ & 0.69 \\
\hline Male Sex & $1806(81)$ & $164(82)$ & 0.71 \\
\hline Deceased & $150(7)$ & $22(11)$ & 0.02 \\
\hline \multicolumn{4}{|l|}{ Ethnicity } \\
\hline White & $967(44)$ & $78(39)$ & \multirow[t]{7}{*}{0.11} \\
\hline Black & $408(18)$ & $50(25)$ & \\
\hline Indigenous & $138(6)$ & $10(5)$ & \\
\hline Asian & $147(7)$ & $20(10)$ & \\
\hline Hispanic & $116(5)$ & $9(5)$ & \\
\hline Other & $82(4)$ & $5(3)$ & \\
\hline Unknown & $362(16)$ & $27(14)$ & \\
\hline \multicolumn{4}{|l|}{ Province } \\
\hline$B C$ & $946(43)$ & $88(44)$ & \multirow[t]{3}{*}{0.49} \\
\hline ON & $870(39)$ & $70(35)$ & \\
\hline QC & $404(18)$ & $41(21)$ & \\
\hline \multicolumn{4}{|l|}{ Risk Factors } \\
\hline MSM & $998(45)$ & $93(47)$ & 0.63 \\
\hline PWID & $467(21)$ & $55(28)$ & 0.03 \\
\hline
\end{tabular}

$B C$ British Colombia, ON Ontario, QC Quebec, MSM Men who have sex with men, PWID people who inject drugs, ADI AIDS defining illness, ARV anti-retroviral therapy

${ }^{a}$ Data shown are frequencies and proportions for categorical variables and median and interquartile ranges for continuous variables. $p$ values for categorical variables were calculated using chi-square or Fisher exact tests and for continuous variables were calculated using Wilcoxon's Rank Sum tests

${ }^{b}$ 'No ADI ever' refers to no recorded ADI's during study period. 'None before/or first ARV date' refers to no recoded ADI prior to study enrollment 
Table 2 HIV-related characteristics of HIV-infected participants by HBV infection status $(N=2419)$

\begin{tabular}{|c|c|c|c|}
\hline Clinical Characteristics & $\begin{array}{l}\mathrm{HIV} \\
\mathrm{N}=2220\end{array}$ & $\begin{array}{l}\text { HIV-HBV } \\
\text { Co-Infected } \\
\mathrm{N}=199\end{array}$ & $p$ value $e^{a}$ \\
\hline \multicolumn{4}{|l|}{ Baseline HIV viral load (Log10 copies/mL) } \\
\hline$<4$ & $332(15)$ & $30(15)$ & \multirow[t]{3}{*}{0.87} \\
\hline $4-5$ & $1011(46)$ & $94(47)$ & \\
\hline$>5$ & $877(40)$ & $75(38)$ & \\
\hline \multicolumn{4}{|c|}{ End of follow-up HIV viral load (Log10 copies/mL) } \\
\hline$<4$ & $2104(95)$ & $193(97)$ & \multirow[t]{3}{*}{0.38} \\
\hline $4-5$ & $69(3)$ & $4(2)$ & \\
\hline$>5$ & $47(2)$ & $2(1)$ & \\
\hline Baseline CD4 T cell count (cells/mm³) & $235(120-360)$ & $188(85-294)$ & 0.0002 \\
\hline \multicolumn{4}{|c|}{ Baseline CD4 T cell count category (cells/mm³) } \\
\hline$\leq 199$ & $897(40)$ & $105(53)$ & \multirow[t]{4}{*}{0.002} \\
\hline 200-349 & $720(32)$ & $60(30)$ & \\
\hline $350-499$ & $367(17)$ & $24(12)$ & \\
\hline$>500$ & $236(11)$ & $10(5)$ & \\
\hline \multicolumn{4}{|l|}{ Baseline AIDS-Defining IIIness ${ }^{b}$} \\
\hline$\geq 1$ & $446(20)$ & $55(28)$ & \multirow[t]{2}{*}{0.01} \\
\hline None & $1774(80)$ & $144(72)$ & \\
\hline Years on ARV therapy & $5.01(2.50-8.75)$ & $5.97(3.11-9.94)$ & 0.003 \\
\hline HIV Suppressed since FARVDT & $2040(92)$ & $190(96)$ & 0.07 \\
\hline HIV Rebound (since first VS) & $481(24)$ & $56(29)$ & 0.07 \\
\hline
\end{tabular}

VS virological suppression, FARVDT first naïve ARV date

${ }^{a}$ Data shown are frequencies and proportions for categorical variables and median and interquartile ranges for continuous variables. $p$ values for continuous variables were calculated using chi-square or Fisher exact tests and for continuous variables were calculated using Wilcoxon's Rank Sum tests

${ }^{\mathrm{b}}$ AIDS-defining illness present prior to or before first naïve ARV date

The overall mortality rate by end of follow-up was 7.1\%. HIV-HBV co-infected participants had a higher mortality rate $(11 \%$ vs. $7 \%, p=0.02)$. The mortality rate among participants with clinically relevant fibrosis at baseline was higher $(23 \%$ vs $6 \%, p<0.0001)$.

\section{Discussion}

Our study is among the first to describe the epidemiology of HIV-HBV co-infection in Canada at the time of ARV initiation. Our cohort included approximately $20 \%$ of all HIV-infected individuals in Canada and is largely representative of those initiating ARV since 2000 [15]. The prevalence of HIV-HBV co-infection in our analysis was $8 \%$, which is consistent with previously established co-infection rates in the general Canadian population and reported by other North American HIV cohorts [1, 10-12, 21-23]. This is slightly greater than the $5.5 \%$ rate determined by the Northern Alberta cohort, which likely represents interregional differences in co-infection prevalence [1].

Despite the existence of universal HBV vaccination programs in Canada, the number of reported cases of HBV infection continues to increase, driven primarily by non-Canadian born immigrants $[1,14]$. Many of the
Canadian-born patients in our cohort were likely too old to have received HBV immunization in their youth as this practice in Canada did not begin until the 1990s [24-26]. There were no statistically significant differences in the racial distribution of the HIV-HBV coinfected group compared to HIV mono-infected cohort participants. We acknowledge that the large proportion of missing data on race may have affected these results. However, our findings are in keeping with the Northern Alberta cohort, in which the majority of HIV-HBV coinfected males were White, and females were mainly Black or Indigenous [1]. The rate of acute HBV in Indigenous persons in Canada is approximately three times that of non-Indigenous persons [14, 27]. However, in our cohort of HIV-infected participants, the rate of HBV co-infection among Indigenous people was comparable to the general population.

The high prevalence of MSM and PWID in our cohort is in keeping with other studies in areas with low HBV endemicity $[10,11,28]$. The prevalence of HCV infection and injection drug use in our cohort was higher among participants with HIV-HBV co-infection compared to HIV infected patients, which is consistent with 
Table 3 Liver-Specific characteristics of HIV-infected participants by HBV infection status $(N=2419)$

\begin{tabular}{|c|c|c|c|}
\hline Clinical Characteristics & HIV N $=2220$ & HIV-HBV Co-Infected N = 199 & $p$ value $^{a}$ \\
\hline Hepatitis C co-infection & $520(23)$ & $61(31)$ & 0.02 \\
\hline Baseline AST (IU/L) & $29(23-41)$ & $36(26-62)$ & $<0.0001$ \\
\hline \multicolumn{4}{|l|}{ Baseline AST category } \\
\hline Normal (10-40 IU/L) & $1649(74)$ & $120(60)$ & \multirow[t]{2}{*}{$<0.0001$} \\
\hline Elevated (> $40 \mathrm{IU} / \mathrm{L})$ & $571(26)$ & $79(40)$ & \\
\hline End of follow-up AST & $25(20-33)$ & $26(20-38)$ & 0.14 \\
\hline \multicolumn{4}{|l|}{ End of follow-up AST category } \\
\hline Normal (10-40 IU/L) & $1855(84)$ & $152(76)$ & \multirow[t]{2}{*}{0.01} \\
\hline Elevated (> $40 \mathrm{IU} / \mathrm{L})$ & $365(17)$ & $47(24)$ & \\
\hline Baseline APRI & $0.37(0.27-0.59)$ & $0.50(0.35-1.04)$ & $<0.0001$ \\
\hline \multicolumn{4}{|l|}{ Baseline APRI Fibrosis category } \\
\hline$\leq 0.5$ (minimal) & $1501(68)$ & $99(50)$ & \multirow[t]{4}{*}{$<0.0001^{b}$} \\
\hline 0.51-1.49 (moderate) & $593(27)$ & $68(34)$ & \\
\hline 1.50-1.99 (significant) & $34(2)$ & $8(4)$ & \\
\hline$\geq 2.0$ (advanced/cirrhosis) & $92(4)$ & $24(12)$ & \\
\hline End of follow-up APRI & $0.30(0.22-0.43)$ & $0.32(0.23-0.56)$ & 0.03 \\
\hline \multicolumn{4}{|c|}{ End of follow-up APRI Fibrosis category } \\
\hline$\leq 0.5$ (minimal) & $1831(82)$ & $145(73)$ & \multirow[t]{4}{*}{$0.005^{b}$} \\
\hline 0.51-1.49 (moderate) & $302(14)$ & $39(20)$ & \\
\hline 1.50-1.99 (significant) & $24(1)$ & $3(2)$ & \\
\hline$\geq 2.0$ (advanced/cirrhosis) & $63(3)$ & $12(6)$ & \\
\hline
\end{tabular}

AST aspartate aminotransferase, APRI aspartate aminotransferase to platelet ratio index, VS virological suppression, FARVDT first naïve ARV date aData shown are frequencies and proportions for categorical variables and median and interquartile ranges for continuous variables. $\mathrm{p}$ values for continuous variables were calculated using chi-square or Fisher exact tests and for continuous variables were calculated using Wilcoxon's Rank Sum tests ${ }^{\mathrm{b}} p$ values were calculated using Kruskal-Wallis rank tests

other viral hepatitis-HIV co-infection studies [11, 29, 30]. The proportion of MSM did not differ between HIV-infected and HIV-HBV co-infected groups. While this is in alignment with Pittman et al, who found no independent association between MSM and HBV coinfection, [1] other HIV cohorts have reported a higher proportion of MSM among patients who are HIV-HBV co-infected $[12,28]$. We speculate our data may represent a shift in epidemiology in which HBV infection is more related to injection drug use rather than sexual transmission among the HIV-infected population in Canada.

HBV infection is often asymptomatic and as many as $30 \%$ of patients have no identified risk factors for exposure, thereby making screening necessary to identify HBV infection $[14,31,32]$. As $10 \%$ of patients in CANOC had unknown HBV status, there is a continuing need to bolster screening efforts in this population [33]. Knowledge of HBV co-infection is also highly relevant to decisions related to ARV selection.

We demonstrated lower baseline CD4 T cell counts and an increased rate of ADI among HIV-HBV coinfected patients compared to HIV-infected patients.
Our observation of lower baseline CD4 T cell counts in HIV-HBV co-infected patients has been replicated in some, [34-36] but not all, analyses [13, 35, 37, 38]. Lower CD4 counts in HIV-HBV co-infected individuals have been associated with higher levels of HBV viral replication (HBV DNA > 200,000 IU/mL) and may increase the risk of developing hepatocellular carcinoma [12, 39]. HIV-HBV co-infected individuals had a higher prevalence of $\mathrm{HCV}$ co-infection. $\mathrm{HCV}$ co-infection may negatively influence CD4 $\mathrm{T}$ cell counts in HIV-infected patients [22, 40, 41]. This may have contributed to a lower baseline CD4 $\mathrm{T}$ cell count in the HBV-HIV coinfected group. However, several studies that controlled for ARV therapy, baseline clinical characteristics, and other potential confounders did not demonstrate any differences in ADI or CD4 $\mathrm{T}$ cell recovery [42-45]. It is also plausible that CD4 $\mathrm{T}$ cell counts may have been reduced by splenic sequestration [46-48].

Clinically relevant fibrosis at baseline was prevalent in $20 \%$ of HIV-HBV co-infected participants. We demonstrated that HBV co-infection and older age were associated with baseline clinically relevant fibrosis. This is in keeping with other studies that have used non-invasive 
Table 4 Logistic regression model showing factors associated with clinically relevant fibrosis at baseline $(\mathrm{N}=2419)$

\begin{tabular}{|c|c|c|c|c|c|c|}
\hline \multirow[b]{3}{*}{ Variable } & \multicolumn{6}{|c|}{ APRI> 1.5 (clinically relevant fibrosis) at baseline } \\
\hline & \multicolumn{3}{|c|}{ Univariate Analysis } & \multicolumn{3}{|c|}{ Multivariable Analysis } \\
\hline & OR & $95 \% \mathrm{Cl}$ & Wald $p$ & OR & $95 \% \mathrm{Cl}$ & Wald $p$ \\
\hline \multicolumn{7}{|l|}{ Hepatitis B } \\
\hline HBV negative & & Reference & & & Reference & \\
\hline HBV positive & 3.18 & $2.10-4.84$ & $<0.0001$ & 3.08 & $1.99-4.78$ & $<0.001$ \\
\hline \multicolumn{7}{|l|}{ Hepatitis C } \\
\hline HCV negative & & Reference & & & Reference & \\
\hline HCV positive & 4.77 & $3.43-6.63$ & $<0.0001$ & 4.55 & $3.26-6.35$ & $<0.001$ \\
\hline
\end{tabular}

Baseline AIDS

No ADI ever

None before/at FARVDT

1.49

$\geq 1$ before/at FARVDT

1.63

Race

White

Black

Indigenous

Asian

Hispanic

Other

Unknown

Birth sex

Female

Male

Province

BC

ON

QC

Years on ARV

Age at first ARV

MSM

PWID

Baseline HIV viral load (log10 copies $/ \mathrm{mL})$

$\begin{array}{ll}<4 & \\ 4-5 & 1.68 \\ >5 & 2.46\end{array}$

Baseline CD4 count (cells/mm³)

$>500$

350-499

200-349

2.76

$\leq 100$
Reference

0.74-2.98

$0.77-3.46$

Reference

0.23-0.70

0.61-2.09

0.33-1.36

0.01

0.09-0.93

0.66-2.80

0.56-1.38

Reference

0.70-1.62

0.78

Reference

0.32-0.68

$<0.0001$

0.26-0.72

0.98-1.06

1.01-1.04

0.46-0.88

2.49-4.82

Reference

0.91-3.08

$1.35-4.48$

Reference

0.70-3.70

0.85-3.92

0.0007
0.37

0.003

0.006

$<0.0001$

1.32-5.77

$1.00-1.04$

$-$

Reference

0.004

1.49

0.80-2.77

2.15

1.16-3.97
0.21

0.01

0.02

FARVDT first naïve ARV date, MSM Men who have Sex with Men, PWID People Who Infect Drugs, $B C$ British Colombia, ON Ontario, OC Quebec Variables considered in the multivariate model included: hepatitis B, hepatitis $C$, race, province, age at first ARV treatment, MSM, baseline HIV viral load, baseline CD4 count. Due to co-linearity with hepatitis C, PWID was not included in the final model 
Table 5 Logistic regression model showing factors associated with clinically relevant fibrosis at end of study follow-up ( $\mathrm{N}=2419$ )

\begin{tabular}{|c|c|c|c|c|c|c|}
\hline \multirow[b]{3}{*}{ Variable } & \multicolumn{6}{|c|}{ APRI> 1.5 (clinically relevant fibrosis) at end of follow-up } \\
\hline & \multicolumn{3}{|c|}{ Univariate Analysis } & \multicolumn{3}{|c|}{ Multivariable Analysis } \\
\hline & OR & $95 \% \mathrm{Cl}$ & Wald $p$ & OR & $95 \% \mathrm{Cl}$ & Wald $p$ \\
\hline \multicolumn{7}{|l|}{ Hepatitis B } \\
\hline Never co-infected & & Reference & & & - & \\
\hline Ever co-infected & 2.00 & $1.13-3.53$ & 0.02 & & & \\
\hline \multicolumn{7}{|l|}{ Hepatitis C } \\
\hline Never co-infected & & Reference & & & Reference & \\
\hline Ever co-infected & 7.03 & $4.61-10.74$ & $<0.0001$ & 6.35 & $4.12-9.79$ & $<0.0001$ \\
\hline \multicolumn{7}{|l|}{ Baseline AIDS } \\
\hline No ADI ever & & Reference & & & & \\
\hline None before/at FARVDT & 1.72 & $0.69-4.31$ & 0.41 & & - & \\
\hline$\geq 1$ before/at FARVDT & 1.95 & $0.73-5.19$ & & & & \\
\hline \multicolumn{7}{|l|}{ Race } \\
\hline White & & Reference & & & & \\
\hline Black & 0.28 & $0.12-0.65$ & & & & \\
\hline Indigenous & 1.83 & $0.95-3.54$ & & & & \\
\hline Asian & 0.77 & $0.33-1.84$ & 0.009 & & - & \\
\hline Hispanic & 0.51 & $0.16-1.67$ & & & & \\
\hline Other & 1.00 & $0.35-2.84$ & & & & \\
\hline Unknown & 1.31 & $0.78-2.18$ & & & & \\
\hline \multicolumn{7}{|l|}{ Birth sex } \\
\hline Female & & Reference & & & - & \\
\hline Male & 0.69 & $0.43-1.10$ & 0.12 & & & \\
\hline \multicolumn{7}{|l|}{ Province } \\
\hline$B C$ & & Reference & & & & \\
\hline ON & 0.44 & $0.28-0.70$ & 0.0001 & & - & \\
\hline QC & 0.34 & $0.17-0.67$ & & & & \\
\hline Years on ARV & 0.97 & $0.92-1.02$ & 0.26 & & - & \\
\hline Age at first ARV & 1.01 & $0.99-1.02$ & 0.21 & & - & \\
\hline MSM & 0.34 & $0.26-0.60$ & $<0.0001$ & & - & \\
\hline PWID & 5.05 & $3.37-7.56$ & $<0.0001$ & & - & \\
\hline Baseline HIV viral load (Log10 copies/mL) & & & 0.17 & & & \\
\hline$<4$ & & Reference & & & - & \\
\hline $4-5$ & 1.46 & $0.72-2.93$ & & & & \\
\hline$>5$ & 1.87 & $0.94-3.74$ & & & & \\
\hline \multicolumn{7}{|l|}{ Follow-up HIV viral load (Log10 copies/mL) } \\
\hline$<4$ & & Reference & & & Reference & \\
\hline $4-5$ & 3.33 & $1.54-7.16$ & $<0.0001$ & 2.27 & $1.01-5.10$ & $<0.0001$ \\
\hline$>5$ & 8.80 & $4.41-17.43$ & & 7.33 & $3.46-15.51$ & \\
\hline \multicolumn{7}{|l|}{ Baseline CD4 count (cells/mm³) } \\
\hline$\leq 100$ & & Reference & & & Reference & \\
\hline $200-349$ & 0.55 & $0.35-0.86$ & & 0.62 & $0.38-0.99$ & \\
\hline $350-499$ & 0.15 & $0.06-0.42$ & 0.0001 & 0.18 & $0.07-0.51$ & 0.004 \\
\hline$>500$ & 0.37 & $0.16-0.86$ & & 0.55 & $0.23-1.32$ & \\
\hline
\end{tabular}

FARVDT first naïve ARV date, MSM Men who have Sex with Men, PWID People Who Infect Drugs

$B C$ British Colombia, ON Ontario, QC Quebec

Variables considered in the multivariate model included: hepatitis B, hepatitis C, race, province, age at first ARV treatment, MSM, follow-up HIV viral load, baseline CD4 count. Due to co-linearity with hepatitis C, PWID was not included in the final model 
measures to determine the extent of fibrosis in HIVHBV co-infected patients [36, 49, 50]. While fibrosis scores improved in all participants during follow-up, there was a greater regression among HIV-HBV coinfected patients. At the end of follow-up (median 5.97 years among HIV-HBV co-infected participants) HBV co-infection was no longer independently associated with fibrosis. This is consistent with previous studies of 1-3 years involving HBV-HIV co-infected patients demonstrating that HBV-active antiretroviral therapy reduces inflammation and fibrosis by suppressing HBV infection [51-55]. Our results suggest that fibrosis in HBV-HIV co-infected patients may continue to normalize years after initiating ARV therapy.

Patients who had high baseline HIV RNA levels were more likely to have clinically relevant fibrosis, both at baseline and at end of follow-up. Baseline CD4 T cell count was not a predictor of clinically relevant fibrosis by multivariable analysis. The influence of HIV on progression of HBV-related liver disease has been attributed to a number of mechanisms including direct infection of hepatic cells, [56] indirectly through ARV hepatotoxicity $[57,58]$, CD4 T cell depletion causing cytokine deregulation and inflammation [59] and/or impaired $\mathrm{T}$ cell response [60]. The demonstrated association between fibrosis and HIV RNA level prior to ARV therapy, but not CD4 T cell count, lends support to a direct effect of HIV infection on fibrosis that is distinct from an effect on $\mathrm{T}$-cell response or drug toxicity.

Several studies have suggested an inverse correlation between CD4 T cell count and fibrosis in HBV-HIV coinfection, [46-48] as well as an association between low baseline CD4 $\mathrm{T}$ cell counts and increased liver-related mortality $[7,12]$. Our analysis did not identify an association between low CD4 T cell counts and clinically relevant fibrosis at baseline. This may suggest that the decreased CD4 T cell counts were not a cause of fibrosis but rather a result of splenic sequestration of leukocytes due to portal hypertension [46-48]. We did demonstrate that low baseline CD4 T cell counts were associated with fibrosis at end of follow-up, which is consistent with findings of a previous prospective study of HIV-HBV coinfected patients followed for a median of five years [61]. While it would be of interest to compare fibrosis with CD4 $\mathrm{T}$ cell counts at end of follow-up, CD4 T cells counts were only recorded at baseline.

We observed higher mortality among HIV-HBV coinfected participants compared to HIV-infected individuals. We suspect that this is due in part to a consequence of excess liver-disease related mortality [7-10, 62]. While we could not confirm this as liver-specific mortality is not captured in CANOC, we did demonstrate increased fibrosis among HIV-HBV co-infected participants, and that participants with APRI> 1.5 were more likely to be deceased at follow-up. This is consistent with previous work [63].

Certain limitations are acknowledged. There was a large proportion of missing data due to incomplete or unknown HBV infection testing and lack of baseline APRI measurements. Although we did not identify any large differences between our analysis set and excluded patients it is possible that unrecognized biases may have influenced our findings. The lower proportion of PWID in our analysis sample may have biased the proportion with HBV co-infection as injection drug use is a known risk factor for HBV exposure. As APRI scores were our primary study outcome, we opted for complete case analysis to address missing data concerns. We did not have access to data including HBV infection date, repeated HBV infection tests, and HBV treatment. Alcohol consumption information, a potentially important confounder for fibrosis evaluation, was not available. We cannot necessarily generalize our findings to patients starting ARV prior to January 2000. Our study includes data from three provinces. Efforts to include more Canadian regions have been made and the next CANOC dataset will include greater regional representation, which will increase the generalizability of this cohort.

\section{Conclusion}

Our evaluation demonstrates a HBV co-infection prevalence of $8 \%$ in HIV-infected patients in BC, Ontario, and Quebec. HIV-HBV co-infected participants were more likely to have a history of injection drug use and to be HCV co-infected. HIV-HBV co-infected participants had lower CD4 $\mathrm{T}$ cell counts at baseline and higher levels of hepatic fibrosis scores compared to HIV-infected patients. However, among patients receiving ARV therapy, there was no clinically significant difference in fibrosis at the end of follow up between HIV-HBV co-infected and HIV-infected individuals. Our results help illuminate the clinical and demographic characteristics of this understudied population. The prevalence and clinical correlates of HIV-HBV co-infection, namely reduced CD4 T cell count and fibrosis, reinforce the need for routine HBV screening among HIV-infected patients.

\section{Supplementary information}

Supplementary information accompanies this paper at https://doi.org/10. 1186/s12879-019-4617-8.

Additional file 1: Table S1. Demographic characteristics participants by inclusion status $(N=10,447)$.

\section{Abbreviations}

ADI: AIDS defining illness; APRI: AST to Platelet Ratio Index; ARV: antiretroviral therapy; AST: aspartate aminotransferase; BC: British Columbia;

CANOC: Canadian Observational Cohort Collaboration; CD4: cluster of differentiation 4; Cl: confidence interval; DNA: deoxyribonucleic acid; HBV: Hepatitis B virus; HCV: Hepatitis C virus; HIV: Human Immunodeficiency 
Virus; IQR: interquartile range; MSM: men who have sex with men; OR: odds ratio; PWID: people who inject drugs; RNA: ribonucleic acid; VL: viral load

\section{Acknowledgements}

We would like to thank all participants for allowing their information to be a part of the CANOC Collaboration.

\section{Authors' contributions}

UR, MD, AW, SW, MK, DK, ML, RT, SS, AK, NM, RH, CC made substantial contributions to the conception, design, drafting and revisioning of the manuscript. PS, SP, ED, MG made substantial contributions to data acquisition, analysis and interpretation. All authors read and approved the final manuscript.

\section{Funding}

The CANOC Centre is supported by the Canadian Institutes of Health Research (CIHR) and the CIHR Canadian HIV Trials Network (CTN 242). The funding body had no role in the study design, the collection, analysis and interpretation of data or in writing the manuscript.

\section{Availability of data and materials}

The datasets generated and/or analyzed during the current study are not publicly available due privacy policies but are available from the corresponding author on reasonable request.

\section{Ethics approval and consent to participate}

Each site conducts data collection with local research ethics approval. Our participation in this study was submitted to and approved by the Ottawa Health Science Network Research Ethics Board (OHSN-REB)(2010673-01H). Informed consent was deemed unnecessary according to OHSN-REB Standard Operating Procedure 701.002, Section 5.8 - "Waiver or Alteration of Informed Consent."

\section{Consent for publication}

Not Applicable.

\section{Competing interests}

The authors declare that they have no competing interests.

\section{Author details}

${ }^{1}$ School of Epidemiology and Public Health, University of Ottawa, Ottawa, ON K1G 5Z3, Canada. ${ }^{2}$ College of Osteopathic Medicine, Michigan State University, East Lansing, Ml 48824, USA. ${ }^{3}$ Department of Medicine, University of Ottawa, Ottawa, ON K1H 8M5, Canada. ${ }^{4}$ BC Centre for Excellence in HIV/ AIDS, Vancouver, BC V6Z 1Y6, Canada. ${ }^{5}$ Regina Qu'Appelle Health Region, Regina, SK, Canada. ${ }^{6}$ University Health Network, Toronto, ON M5G 2C4, Canada. ${ }^{7}$ Research Institute of McGill University Health Centre, Montreal, QC H3H 2L9, Canada. ${ }^{8}$ Memorial University of Newfoundland, Saint John's, NL A1C 5S7, Canada. ${ }^{9}$ Maple Leaf Medical Clinic, Toronto, ON M5G 1K2, Canada. ${ }^{10}$ Clinique Medicale I'Actuel, Montreal, QC H2L 4P9, Canada. ${ }^{11}$ Department of Medicine, University of Saskatchewan, Saskatoon, Saskatchewan S7N 5E5, Canada. ${ }^{12}$ The Ontario HIV Treatment Network, Toronto, ON M4T 1X3, Canada. ${ }^{13}$ Clinique de Médicine Urbaine du Quartier Latin, Montreal, QC H2L 4E9, Canada

Received: 5 February 2019 Accepted: 4 November 2019 Published online: 21 November 2019

\section{References}

1. Pittman C, Plitt S, Birse T, Doucette K, Romanowski B, Cooper R, et al. Prevalence and correlates of HIV and hepatitis B virus coinfection in northern Alberta. Canadian J Infect Dis Med Microbiol. 2014;25(1):e8-e13.

2. Bourgeois A, Edmunds M, Awan A, Jonah L, Varsaneux O, Siu W. Can we eliminate HIV?: HIV in Canada-surveillance report, 2016. Can Commun Dis Rep. 2017;43(12):248

3. Puoti M, Airoldi M, Bruno R, Zanini B, Spinetti A, Pezzoli C, et al. Hepatitis B virus co-infection in human immunodeficiency virus-infected subjects. AIDS Rev. 2002:4(1):27-35.

4. Gillis J, Cooper C, Rourke S, Rueda S, O'Brien K, Collins E, et al. Impact of hepatitis $B$ and $C$ co-infection on health-related quality of life in HIV positive individuals. Qual Life Res. 2013;22(7):1525-35.
5. Alter MJ. Epidemiology of viral hepatitis and HIV co-infection. J Hepatol. 2006:44:56-9.

6. Spradling P, Richardson J, Buchacz K, Moorman A, Brooks J, Investigators HOS. Prevalence of chronic hepatitis B virus infection among patients in the HIV outpatient study, 1996-2007. J Viral Hepat. 2010;17(12):879-86.

7. Thio CL, Seaberg EC, Skolasky R Jr, Phair J, Visscher B, Muñoz A, et al. HIV-1, hepatitis $B$ virus, and risk of liver-related mortality in the multicenter cohort study (MACS). Lancet. 2002;360(9349):1921-6.

8. Salmon-Ceron D, Lewden C, Morlat P, Bévilacqua S, Jougla E, Bonnet F, et al. Liver disease as a major cause of death among HIV infected patients: role of hepatitis C and B viruses and alcohol. J Hepatol. 2005;42(6):799-805.

9. Marin B, Thiébaut R, Bucher HC, Rondeau V, Costagliola D, Dorrucci M, et al. Non-AIDS-defining deaths and immunodeficiency in the era of combination antiretroviral therapy. AIDS (London, England). 2009;23(13):1743.

10. Hoffmann CJ, Seaberg EC, Young S, Witt MD, D'Acunto K, Phair J, et al. Hepatitis B and long-term HIV outcomes in co-infected HAART recipients. AIDS (London, England). 2009:23(14):1881.

11. Gilson RJ, Hawkins AE, Beecham MR, Ross E, Waite J, Briggs M, et al. Interactions between HIV and hepatitis B virus in homosexual men: effects on the natural history of infection. Aids. 1997;11(5):597-606.

12. Konopnicki D, Mocroft A, De Wit S, Antunes F, Ledergerber B, Katlama C, et al. Hepatitis B and HIV: prevalence, AIDS progression, response to highly active antiretroviral therapy and increased mortality in the EuroSIDA cohort. Aids. 2005;19(6):593-601.

13. Nikolopoulo GK, Paraskevis D, Hatzitheodorou E, Moschidis Z, Sypsa V, Zavitsanos $X$, et al. Impact of hepatitis B virus infection on the progression of AIDS and mortality in HIV-infected individuals: a cohort study and metaanalysis. Clin Infect Dis. 2009;48(12):1763-71.

14. Canada PHAo. In: Brief report: hepatitis B infection in Canada; 2011.

15. Palmer AK, Klein MB, Raboud J, Cooper C, Hosein S, Loutfy M, et al. Cohort profile: the Canadian observational cohort collaboration. Int J Epidemiol. 2010:40(1):25-32.

16. Al-Mohri H, Cooper C, Murphy T, Klein M. Validation of a simple model for predicting liver fibrosis in HIV/hepatitis C virus-coinfected patients. HIV medicine. 2005;6(6):375-8.

17. Shaheen AAM, Myers RP. Diagnostic accuracy of the aspartate aminotransferase-to-platelet ratio index for the prediction of hepatitis Crelated fibrosis: a systematic review. Hepatol. 2007:46(3):912-21.

18. Wu SD, Wang JY, Li L. Staging of liver fibrosis in chronic hepatitis B patients with a composite predictive model: a comparative study. World J Gastroenterol. 2010;16(4):501-7.

19. Wai CT, Greenson JK, Fontana RJ, Kalbfleisch JD, Marrero JA, Conjeevaram HS, et al. A simple noninvasive index can predict both significant fibrosis and cirrhosis in patients with chronic hepatitis C. Hepatol. 2003;38(2):518-26.

20. Ward M, Buehler MJW, Jaffe MHW, Berkelman RL. 1993 revised classification system for HIV infection and expanded surveillance case definition for AIDS among adolescents and adults; 1993.

21. Wandeler G, Gsponer T, Bihl F, Bernasconi E, Cavassini M, Kovari H, et al. Hepatitis B virus infection is associated with impaired immunological recovery during antiretroviral therapy in the Swiss HIV cohort study. J Infect Dis. 2013;208(9):1454-8.

22. Greub G, Ledergerber B, Battegay M, Grob P, Perrin L, Furrer H, et al. Clinical progression, survival, and immune recovery during antiretroviral therapy in patients with HIV-1 and hepatitis C virus coinfection: the Swiss HIV cohort study. Lancet. 2000;356(9244):1800-5.

23. Soriano V, Puoti M, Bonacini M, Brook G, Cargnel A, Rockstroh J, et al. Care of patients with chronic hepatitis B and HIV co-infection: recommendations from an HIV-HBV international panel. Aids. 2005;19(3):221-40.

24. Statement on Hepatitis B Virus Vaccine. Health Welf Can. 1982:221-4.

25. Macdonald N. Moving towards a universal hepatitis B vaccine program for Canadian children. Can J Infect Dis. 1995;6(3):129-30.

26. Zhang J, Zou S, Giulivi A. Epidemiology of hepatitis B in Canada. Can J Infect Dis. 2001;12(6):345-50

27. Osiowy C, Giles E, Trubnikov M, Choudhri Y, Andonov A. Characterization of acute and chronic hepatitis B virus genotypes in Canada. PLoS One. 2015; 10(9):e0136074.

28. Kellerman SE, Hanson DL, McNaghten A, Fleming PL. Prevalence of chronic hepatitis $B$ and incidence of acute hepatitis $B$ infection in human immunodeficiency virus-infected subjects. J Infect Dis. 2003;188(4):571-7.

29. Al-Mohri H, Murphy T, Lu Y, Lalonde RG, Klein MB. Evaluating liver fibrosis progression and the impact of antiretroviral therapy in HIV and hepatitis C 
coinfection using a noninvasive marker. JAIDS J Acquir Immune Defic Syndr. 2007:44(4):463-9.

30. Lincoln D, Petoumenos K, Dore G, Database AHO. HIV/HBV and HIV/HCV coinfection, and outcomes following highly active antiretroviral therapy. HIV med. 2003:4(3):241-9.

31. Phung B-C, Sogni P, Launay O. Hepatitis B and human immunodeficiency virus co-infection. World J Gastroenterol: WJG. 2014;20(46):17360.

32. Andonov A, Butler G, Ling R, Prichard L, Baril J, Gale-Rowe M. Primary care management of hepatitis B-quick reference (HBV-QR); 2013.

33. Terrault NA, Lok AS, McMahon BJ, Chang KM, Hwang JP, Jonas MM, et al. Update on prevention, diagnosis, and treatment of chronic hepatitis $B$ AASLD 2018 hepatitis B guidance. Hepatol. 2018;67(4):1560-99.

34. Thio CL, Smeaton L, Saulynas M, Hwang H, Saravan S, Kulkarni S, et al. Characterization of HIV-HBV co-infection in a multi-national HIV-infected cohort. AIDS (London, England). 2013;27(2):191.

35. Idoko J, Meloni S, Muazu M, Nimzing L, Badung B, Hawkins C. Hepatitis B virus co-infection impacts baseline HIV parameters and HAART-related hepatotoxicity risk in an HIV-infected Nigerian cohort. Clin Infect Dis. 2007; 49(8):1268-73.

36. Hawkins C, Christian B, Ye J, Nagu T, Aris E, Chalamilla G, et al. Prevalence of hepatitis $B$ co-infection and response to antiretroviral therapy among HIVinfected patients in Tanzania. Aids. 2013;27(6):919-27.

37. Sarkar J, Saha D, Bandyopadhyay B, Saha B, Kedia D, Mazumder DG, et al. Baseline characteristics of HIV \& hepatitis B virus (HIV/HBV) co-infected patients from Kolkata, India. Indian J Med Res. 2016;143(5):636.

38. Wondimeneh Y, Alem M, Asfaw F, Belyhun Y. HBV and HCV seroprevalence and their correlation with CD4 cells and liver enzymes among HIV positive individuals at University of Gondar teaching hospital. Northwest Ethiop Virol j. 2013;10(1):171

39. Clifford GM, Rickenbach M, Polesel J, Dal Maso L, Steffen I, Ledergerber B, et al. Influence of HIV-related immunodeficiency on the risk of hepatocellular carcinoma. Aids. 2008;22(16):2135-41.

40. Piroth L, Grappin M, Cuzin L, Mouton Y, Bouchard O, Raffi F, et al. Hepatitis C virus co-infection is a negative prognostic factor for clinical evolution in human immunodeficiency virus-positive patients. J Viral Hepat. 2000;7(4):302-8.

41. De Luca A, Bugarini R, Lepri AC, Puoti M, Girardi E, Antinori A, et al. Coinfection with hepatitis viruses and outcome of initial antiretroviral regimens in previously naive HIV-infected subjects. Arch Intern Med. 2002;162(18):2125-32.

42. Rockstroh J, Konopnicki D, Soriano V, Kirk O, Antunes F, Knysz B, et al. Hepatitis B and hepatitis $C$ in the EuroSIDA cohort: prevalence and effect on mortality, AIDS, progression and response to HAART. In: 11th conference on retroviruses and opportunistic infections; 2004.

43. Sulkowski MS, Moore RD, Mehta SH, Chaisson RE, Thomas DL. Hepatitis C and progression of HIV disease. Jama. 2002;288(2):199-206.

44. Bonacini M, Louie S, Bzowej N, Wohl AR. Survival in patients with HIV infection and viral hepatitis B or C: a cohort study. Aids. 2004;18(15):2039-45.

45. Amin J, Kaye M, Skidmore S, Pillay D, Cooper D, Dore G. HIV and hepatitis C coinfection within the CAESAR study. HIV medicine. 2004;5(3):174-9.

46. Hull MW, Rollet K, Odueyungbo A, Saeed S, Potter M, Cox J, et al. Factors associated with discordance between absolute CD4 cell count and CD4 cell percentage in patients coinfected with HIV and hepatitis C virus. Clin Infect Dis. 2012;54(12):1798-805.

47. Shmagel KV, Saidakova EV, Shmagel NG, Korolevskaya LB, Chereshnev VA, Robinson J, Grivel JC, Douek DC, Margolis L, Anthony DD, Lederman MM. Systemic inflammation and liver damage in HIV/hepatitis $C$ virus coinfection. HIV Med. 2016;17(8):581-9. https://doi.org/10.1111/hiv.12357.

48. Mandorfer M, Reiberger T, Payer B, Peck-Radosavljevic M, HIV V, Group LS The influence of portal pressure on the discordance between absolute CD4+ cell count and CD4+ cell percentage in HIV/hepatitis C virusCoinfected patients. Clin Infect Dis. 2013;56(6):904-5.

49. Wandeler G, Mulenga L, Vinikoor MJ, Kovari H, Battegay M, Calmy A, et al. Liver fibrosis in treatment-naive HIV-infected and HIV/HBV co-infected patients: Zambia and Switzerland compared. Int J Infect Dis. 2016;51:97-102.

50. Price JC, Seaberg EC, Badri S, Witt MD, D'acunto K, Thio CL. HIV monoinfection is associated with increased aspartate aminotransferase-to-platelet ratio index, a surrogate marker for hepatic fibrosis. J Infect Dis. 2012;205(6):1005-13.

51. Boyd A, Lasnier E, Molina JM, Lascoux-Combe C, Bonnard P, Miailhes P, et al. Liver fibrosis changes in HIV-HBV-coinfected patients: clinical, biochemical and histological effect of long-term tenofovir disoproxil fumarate use. Antivir Ther. 2010;15(7):963.
52. Stockdale AJ, Phillips RO, Beloukas A, Appiah LT, Chadwick D, Bhagani S, et al. Liver fibrosis by transient elastography and virologic outcomes after introduction of tenofovir in lamivudine-experienced adults with HIV and hepatitis B virus coinfection in Ghana. Clin Infect Dis. 2015;61(6):883-91.

53. Vinikoor MJ, Sinkala E, Chilengi R, Mulenga LB, Chi BH, Zyambo Z, et al. Impact of antiretroviral therapy on liver fibrosis among human immunodeficiency virus-infected adults with and without HBV coinfection in Zambia. Clin Infect Dis. 2017;64(10):1343-9.

54. Audsley J, Robson C, Aitchison S, Matthews GV, Iser D, Sasadeusz J, Lewin SR. Liver Fibrosis Regression Measured by Transient Elastography in Human Immunodeficiency Virus (HIV)-Hepatitis B Virus (HBV)-Coinfected Individuals on Long-Term HBV-Active Combination Antiretroviral Therapy. Open Forum Infect Dis. 2016;3(1):ofw035. https://doi.org/10.1093/ofid/ofw035.

55. Puoti M, Cozzi-Lepri A, Arici C, Moller N, Lundgren J, Ledergerber B, et al. Impact of lamivudine on the risk of liver-related death in 2,041 HBsAg-and HIV-positive individuals: results from an inter-cohort analysis. Antivir Ther. 2006;11(5):567-74.

56. Singh KP, Crane M, Audsley J, Avihingsanon A, Sasadeusz J. Lewin SR. HIVhepatitis B virus coinfection: epidemiology, pathogenesis, and treatment. AIDS (London, England). 2017;31(15):2035-52.

57. Audsley J, Seaberg EC, Sasadeusz J, Matthews GV, Avihingsanon A, Ruxrungtham $\mathrm{K}$, et al. Factors associated with elevated ALT in an international HIV/HBV co-infected cohort on long-term HAART. PLoS One. 2011;6(11):e26482.

58. Ryom L, Lundgren JD, De Wit S, Kovari H, Reiss P, Law M, et al. Use of antiretroviral therapy and risk of end-stage liver disease and hepatocellular carcinoma in HIV-positive persons. Aids. 2016;30(11):1731-43.

59. Glässner A, Eisenhardt M, Kokordelis P, Krämer B, Wolter F, Nischalke HD, et al. Impaired CD4+ T cell stimulation of NK cell anti-fibrotic activity may contribute to accelerated liver fibrosis progression in HIV/HCV patients. J Hepatol. 2013;59(3):427-33.

60. Chang JJ, Sirivichayakul S, Avihingsanon A, Thompson AJ, Revill P, Iser D, et al. Impaired quality of the hepatitis B virus (HBV)-specific T-cell response in human immunodeficiency virus type 1-HBV coinfection. J Virol. 2009; 83(15):7649-58.

61. Boyd A, Bottero J, Miailhes P, Lascoux-Combe C, Rougier H, Girard PM, et al. Liver fibrosis regression and progression during controlled hepatitis $B$ virus infection among HIV-HBV patients treated with tenofovir disoproxil fumarate in France: a prospective cohort study. J Int AIDS Soc. 2017;20(1):21426.

62. Thornton AC, Jose S, Bhagani $S$, Chadwick D, Dunn D, Gilson $R$, et al. Hepatitis B, hepatitis C, and mortality among HIV-positive individuals. AIDS (London, England). 2017;31(18):2525.

63. Jain MK, Seremba E, Bhore R, Dao D, Joshi R, Attar N, et al. Change in fibrosis score as a predictor of mortality among HIV-infected patients with viral hepatitis. AIDS Patient Care STDs. 2012;26(2):73-80.

\section{Publisher's Note}

Springer Nature remains neutral with regard to jurisdictional claims in published maps and institutional affiliations.

Ready to submit your research? Choose BMC and benefit from:

- fast, convenient online submission

- thorough peer review by experienced researchers in your field

- rapid publication on acceptance

- support for research data, including large and complex data types

- gold Open Access which fosters wider collaboration and increased citations

- maximum visibility for your research: over $100 \mathrm{M}$ website views per year

At $\mathrm{BMC}$, research is always in progress.

Learn more biomedcentral.com/submission 